\title{
ANÁLISE DAS MANIFESTAÇÕES PATOLÓGICAS EM UM EDIFÍCIO RESIDENCIAL DA ASA SUL EM BRASÍLIA - DF
}

\author{
NETO, DARY FERREIRA DA SILVA \\ Acadêmico de Engenharia Civil \\ Universidade Estadual de Goiás \\ Goiás; Brasil \\ daryfneto@gmail.com \\ CHATER, LATIF \\ Engenheiro Civil \\ JR \& CHATER ENGENHARIA \\ Brasília, Brasil \\ jrechater@gmail.com
}

\author{
SILVA, JULIANO RODRIGUES \\ Docente de Engenharia Civil \\ Universidade Estadual de Goiás \\ Goiás; Brasil \\ julianorodriguessilva@gmail.com

\section{SCHMIDT, ANDREIA} \\ Engenheira Civil \\ Universidade Fernando Pessoa \\ Porto, Portugal \\ eng.andreiaschmidt@gmail.com
}

\section{RESUMO}

Neste trabalho foi determinado o grau de deterioração estrutural de um edifício residencial de seis pavimentos mais o pilotis, executado em concreto armado e localizado em Brasília-DF. Para a avaliação quantitativa e qualitativa do nível de degradação da estrutura de concreto foi aplicada a metodologia GDE/UnB (2015) - (Grau de Deterioração da Estrutura), concebida em linhas de pesquisa da Universidade de Brasília entre 1994 e 2015. O levantamento das anomalias foi feita através de registros fotográficos, após a divisão do edifício em seis regiões de análise: reservatórios superiores, cobertura, casa de máquinas, pavimentos tipo, pilotis e fachadas. Os resultados obtidos demonstraram que todas as seis regiões de análise possuem grau de deterioração baixo, apesar de o edifício já possuir mais de 60 anos. Foram encontrados valores do grau de deterioração iguais a $\mathrm{G}_{\mathrm{d}}=3,6$ (reservatórios superiores), $\mathrm{G}_{\mathrm{d}}=2,0$ (cobertura), $\mathrm{G}_{\mathrm{d}}=4,9$ (casa de máquinas), $\mathrm{G}_{\mathrm{d}}=4,2$ (pavimentos tipo), $\mathrm{G}_{\mathrm{d}}=7,8$ (pilotis) e $\mathrm{G}_{\mathrm{d}}=6,0$ (fachadas). A análise global da estrutura, considerada a ponderação das famílias de elementos, apontou um baixo nível de degradação estrutural, totalizando o valor de $\mathrm{G}_{\mathrm{d}}=$ 15,0 , ainda que o valor obtido corresponda numericamente à transição entre os graus de deterioração baixo e médio conforme a literatura. Concluiu-se que a metodologia GDE/UnB (2015) teve êxito na avaliação do grau de deterioração do edifício objeto deste estudo, mediante o apontamento da existência de diferentes manifestações patológicas. Com a determinação dos níveis de degradação estrutural local e global, foram apresentadas sugestões de intervenções a serem aplicadas aos elementos danificados, visando a correção das falhas já existentes e a prevenção de novas deficiências estruturais.

Palavras-chave: avaliação, estrutura, manifestações patológicas, metodologia GDE/UnB.

\section{ABSTRACT}

In this study it was determined the degree of structural deterioration of a residential building of six floors and the pilotis, executed in reinforced concrete and located in Brasília-DF. For the quantitative and qualitative evaluation of the level of degradation of the concrete structure was applied the GDE/UnB methodology (2015) - (Degree of Deterioration of the Structure), conceived in research lines of the University of Brasilia between 1994 and 2015. The survey of the anomalies was made through photographic records, after the division of the building into six regions of analysis: upper reservoirs, roof, engine room, type floors, pilotis and facades. The results obtained showed that all the six regions of analysis have a low degree of deterioration, despite the fact that the building already has more than 60 years old. It were found values of degree of deterioration equal to $\mathrm{Gd}=3,6$ (upper reservoirs), $\mathrm{Gd}=2,0$ (roof), $\mathrm{Gd}=4,9$ (engine room), $\mathrm{Gd}=4,2$ (type floors), $\mathrm{Gd}=7,8$ (pilotis) and $\mathrm{Gd}=6,0$ (facades). The global analysis of the structure, considering the pondering of the families of elements, showed a low level of structural degradation, totaling the value of $\mathrm{Gd}=15,0$, although the value obtained corresponds numerically to the transition between the degrees of deterioration low and medium, according to the literature. It was concluded that the GDE/UnB methodology (2015) was successful in evaluating the degree of deterioration of the building of this study, by pointing out the existence of different pathological manifestations. With the determination of the levels of local and global structural degradation, suggestions of interventions to be applied to the damaged elements were presented, aiming at the correction of existing failures and the prevention of new structural deficiencies.

Keywords: evaluation, structure, pathological manifestation, GDE/UnB methodology. 


\section{INTRODUÇÃO}

O uso do concreto como material estrutural ocorreu a partir da combinação deste com o aço, de modo que a solidarização entre esses componentes permitiu, às estruturas assim executadas, resistir adequadamente aos esforços de tração e compressão. Segundo Isaia (2005), a possibilidade técnica de executar estruturas mais esbeltas e dotadas de maiores vãos ocorreu devido ao êxito comportamental do concreto armado, seja ele passivo ou ativo.

A prevalência do concreto armado face a outros sistemas estruturais é justificada, sobremaneira, pelas vantagens do concreto. Aliada à facilitada disponibilidade de seus componentes básicos (cimento, água e agregados graúdo e miúdo), destacam-se ainda: a trabalhabilidade em estado fresco, que permite liberdade de formas geométricas em função do projeto arquitetônico sem que haja perda de desempenho estrutural; o elevado grau de rigidez nos pontos de união de peças, conferindo aspecto monolítico ao conjunto estrutural; a elevada resistência mecânica, que apresenta contínuo crescimento no decorrer do tempo; e a utilização de mão de obra e equipamentos sem alto nível de especialização para seu preparo e aplicação em estruturas convencionais.

Entretanto, mesmo com esses benefícios, o concreto não deve ser entendido como um material de durabilidade eterna, pois também carece de intervenções periódicas para manter seu desempenho satisfatório. A inobservância ou ausência de recomendações voltadas à preservação das construções de concreto pode culminar na manifestação de deficiências indicativas de deterioração estrutural, estudadas pelo ramo da Engenharia denominado Patologia das Estruturas.

Conforme Aitcin (2000), a atualização dos estudos de manifestações patológicas em estruturas de concreto deve-se à necessidade de proporcionar o acesso das informações ao trinômio da atividade edilícia: projetistas, fabricantes de insumos e construtores, para que os profissionais citados tenham acesso à mesma literatura técnica, de modo a trabalhar juntos no aperfeiçoamento das estruturas. Os esforços conjugados de todos os envolvidos devem primar pela obtenção de durabilidade, funcionalidade e segurança, parâmetros fundamentais à qualidade da obra (CUNHA et al, 1996).

Assim, o presente estudo, voltado à análise das manifestações patológicas em estruturas de concreto armado, teve como objeto de estudo um edifício localizado na Asa Sul da cidade de Brasília - DF. O edifício, de ocupação residencial, possui 36 apartamentos dispostos em seis pavimentos mais um pilotis.

\subsection{Objetivo geral}

Analisar as manifestações patológicas de estruturas de concreto existentes em edifício residencial do bairro Asa Sul, em Brasília-DF, utilizando a metodologia GDE/UnB (2015) para determinar o nível de degradação estrutural do objeto de estudo.

\subsection{Objetivos específicos}

- Apresentar as principais manifestações patológicas das estruturas de concreto.

- Determinar o grau de deterioração da estrutura de concreto no todo e em suas partes, de acordo com a metodologia GDE/UnB (2015).

- Exemplificar propostas de intervenção para os elementos identificados como deteriorados, de modo a sugerir alternativas de manutenção preventiva ou corretiva da estrutura.

\section{REFERENCIAL TEÓRICO}

São apresentadas a seguir as principais manifestações patológicas das estruturas de concreto e a metodologia GDE/UnB (2015).

\subsection{Manifestações patológicas das estruturas de concreto}

São abordadas nos tópicos seguintes algumas das manifestações patológicas mais comuns em estruturas de concreto armado. 


\subsubsection{Fissuração}

A NBR 15575-2 (ABNT, 2013) conceitua a fissura de componente estrutural como o seccionamento da superfície ou seção transversal de um elemento estrutural, caracterizada por aberturas decorrentes de tensões normais ou tangenciais. Segundo esta norma, as fissuras manifestadas podem ser consideradas ativas (quando há variação da abertura devido a movimentações diversas da estrutura) ou passivas (quando não há variação dimensional da abertura). A NBR 9575 (ABNT, 2010) define a fissura como a abertura provocada por deformações ou deslocamentos do substrato, subdividas em estáticas ou dinâmicas, sendo manifestações patológicas de amplitude variável, conforme apresentado na Figura 1.

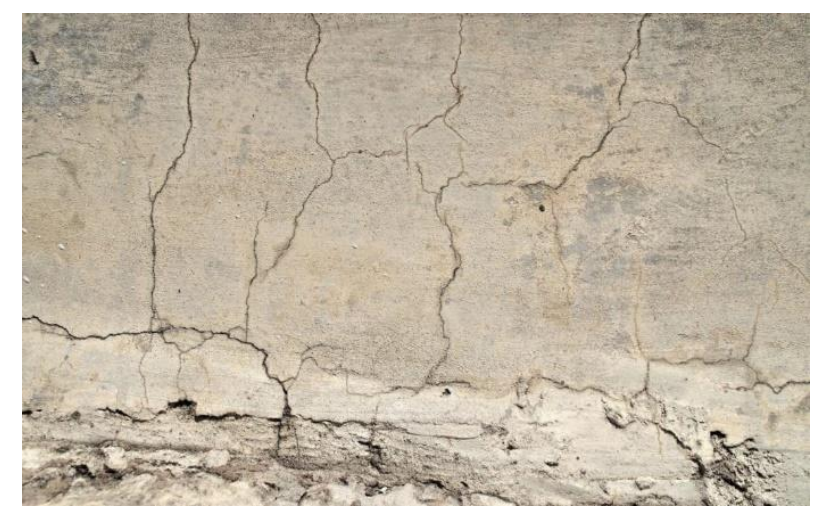

Figura 1: Fissuração provocada por retração de secagem

Fonte: Silva e Jonov (2011)

A primeira e principal classificação das fissuras diz respeito ao comportamento destas, dividindo-as em ativas e passivas. As fissuras ativas correspondem àquelas cuja causa ainda atua sobre a estrutura, respondendo por sua contínua expansão e agravamento; as fissuras passivas remetem àquelas cuja causa cessou, tornando-as estáveis em relação à evolução. A segunda e mais abrangente classificação das fissuras, baseada na espessura de abertura do dano, foi proposta de maneira mais completa por Silva e Jonov (2011), classificando as aberturas estruturais em fissuras, trincas, rachaduras, fendas e brechas, com espessuras variando de $0,5 \mathrm{~mm}$ a $10,0 \mathrm{~mm}$.

\subsubsection{Carbonatação}

Segundo Ribeiro et al (2014), a carbonatação consiste no processo por meio do qual o gás carbônico atmosférico $\left(\mathrm{CO}_{2}\right)$ reage com a água presente no concreto, formando o ácido carbônico $\left(\mathrm{H}_{2} \mathrm{CO}_{3}\right)$ que, ao reagir com os elementos alcalinos do concreto, reduz o pH do concreto para valores inferiores a 9, favorecendo a despassivação das armaduras de aço. $\mathrm{O}$ avanço da carbonatação ocorre a partir da superfície externa do concreto, exposta à ação direta do $\mathrm{CO}_{2}$, conforme representado na Figura 2, e apresenta velocidade decrescente à medida que o gás, por difusão, se utiliza da rede de poros do concreto.

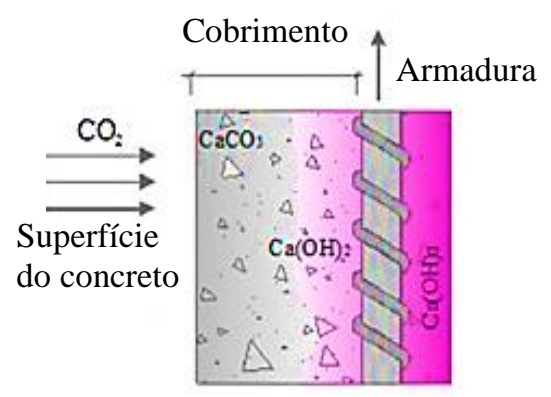

Figura 2: Avanço do processo de carbonatação

Fonte: Modificado de Oliveira et al (2017)

Para a armadura envolvida pelo volume de concreto, os efeitos da carbonatação são bastante prejudiciais. Em contato com o cimento hidratado, forma-se ao redor das barras de aço uma película protetora, denominada camada de passivação, que protege o aço da ação do oxigênio e da umidade. Conforme Neville (2016), a carbonatação, ao neutralizar o pH do 
meio para valores inferiores a 9, acelera a destruição da proteção das barras, expondo a armadura à oxidação e, consequentemente, deteriorando a estrutura como um todo.

Visando mitigar os prejuízos impostos à estrutura, a norma NBR 6118 (ABNT, 2014) recomenda a execução de concretos com relação água/cimento adequada às condições de exposição, como forma de reduzir a permeabilidade e porosidade do concreto, além da execução de elementos com cobrimento nominal não inferior ao mínimo previsto e rígido controle de fissuração das peças.

\subsubsection{Corrosão da armadura}

Cardoso et al (2017) afirmam que a corrosão eletroquímica é a principal responsável pela degradação das armaduras em estruturas de concreto armado. Nessa configuração, verifica-se a formação de regiões de ânodo e cátodo, nas quais ocorrem as reações de oxidação e redução, respectivamente.

Com a progressão do fenômeno corrosivo e a incrustação de oxi-hidróxidos de ferro, o conjunto armadura-ferrugem acaba por ocupar volumes de três a sete vezes o volume das barras originais (RIBEIRO et al, 2014). Este incremento volumétrico da armadura, conforme enunciando pelos autores, origina tensões não previstas no maciço de concreto armado, superiores a $15 \mathrm{MPa}$, que resultam na ruptura do concreto e no colapso estrutural do elemento, segundo retratado na Figura 3.

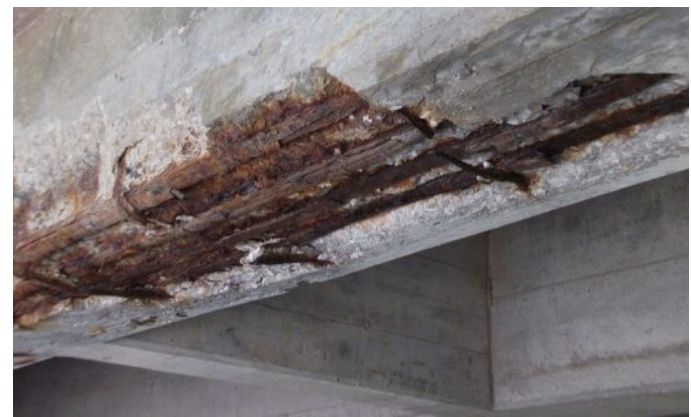

Figura 3: Corrosão da armadura de flexão em viga de concreto armado Fonte: Fusco (2012)

Partindo da premissa de que a corrosão só é desencadeada na presença de oxigênio e umidade, Neville e Brooks (2013) afirmam que a corrosão não se deflagra em ambientes secos, com umidade relativa inferior a 40\%; por outro lado, em meios com umidade relativa superior a $80 \%$, a difusão do oxigênio é dificultada pela saturação do concreto. Logo, segundo os autores, a corrosão é favorecida para condições de umidade relativa entre $70 \%$ e $80 \%$.

\subsubsection{Eflorescência}

Conforme enunciado por Silva e Jonov (2011), a eflorescência consiste em manifestação patológica caracterizada pelo surgimento de manchas, de coloração tipicamente branca, na superfície do concreto, decorrentes do acúmulo superficial de solução saturada de hidróxido de cálcio, tal como apresentado na Figura 4.

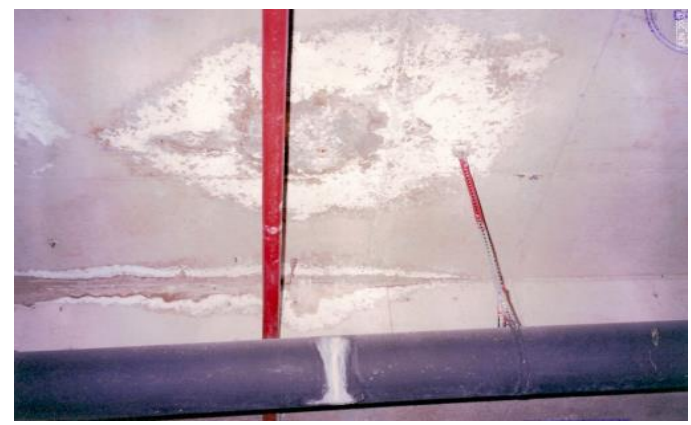

Figura 4: Mancha de eflorescência em laje de concreto aparente Fonte: Caneiro, D’Ávila e Luis (2017) 
Carneiro, D’Ávilae Luis (2017) elencam três fatores cuja ocorrência simultânea resulta na ocorrência da eflorescência no concreto: teor de sais solúveis no interior do concreto; presença de água para dissolver e transportar a solução para a superfície; e diferença de pressão hidrostática entre os meios interno e externo do concreto.

A problemática associada à eflorescência é, em grande parte dos casos, de aspecto estético. Sua ocorrência pode gerar desconforto visual na medida em que a tonalidade das manchas, tipicamente brancas, forma um contraste de cores com o substrato externo, de tonalidade cinza (para estruturas de concreto aparente). Entretanto, por estar associada à percolação de água no interior do concreto, a eflorescência serve como indicativo de risco para a manifestação de outras formas de deterioração do concreto, sobretudo daquelas facilitadas pela fissuração ou elevada porosidade do material.

\subsection{Metodologia GDE/UnB}

A metodologia GDE (Grau de Deterioração da Estrutura) tem sua origem em estudos desenvolvidos no Departamento de Engenharia Civil da Universidade de Brasília, sendo posteriormente incorporada à linha de pesquisa do Programa de PósGraduação em Estruturas e Construção Civil da referida universidade. Deste modo, a metodologia voltada à caracterização do grau de deterioração das estruturas de concreto é denominada metodologia GDE/UnB.

Fundamentalmente baseada em inspeções e análises dos elementos estruturais in loco, a metodologia tem sua aplicabilidade abrangendo as mais diferentes tipologias de estruturas de concreto. Através da divisão da estrutura em famílias de elementos específicos e da aplicação de modelos matemáticos pré-definidos, a metodologia propicia a valoração do grau de deterioração de elementos isolados ou tomados em conjunto. A principal vantagem da análise estrutural dividida em elementos ou famílias destes é a possibilidade de apontar elementos com situação estrutural mais crítica, sob o ponto de vista da estabilidade, devido às diferentes valorações do grau de deterioração estrutural. Consequentemente, a metodologia serve como embasamento para orientar a priorização de intervenções corretivas em partes específicas da estrutura, sob a perspectiva técnica e financeira. Sua aplicação segue o fluxograma apresentado na Figura 5.

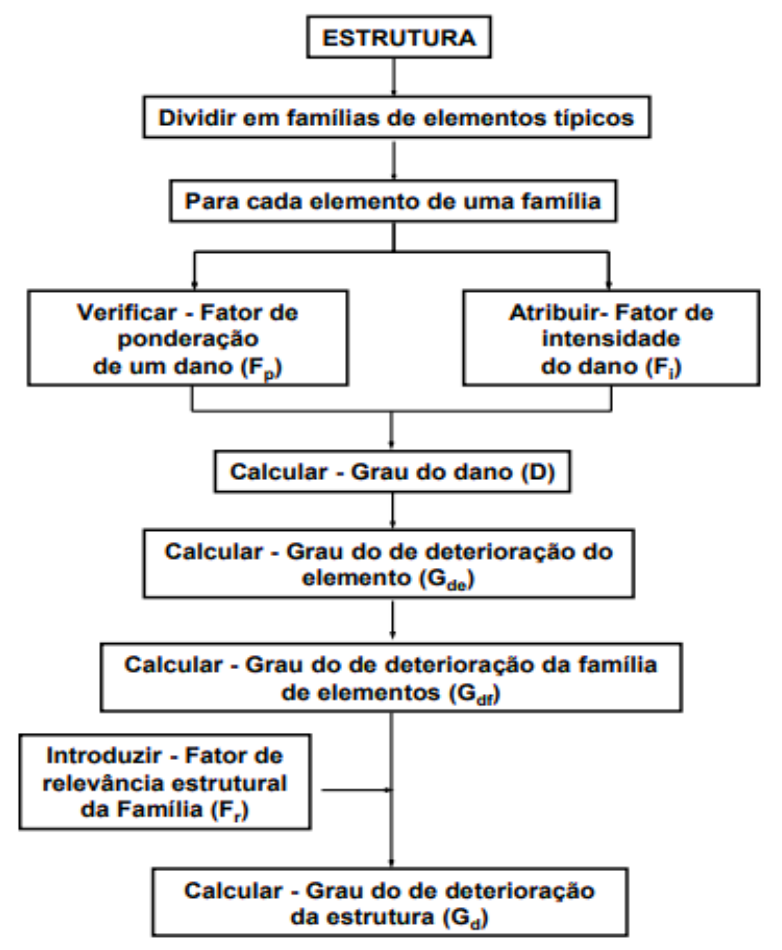

Figura 5: Fluxograma da metodologia GDE/UnB para o cálculo do grau de deterioração estrutural Fonte: Castro (1994)

O Fator de ponderação do dano $\left(\mathrm{F}_{\mathrm{p}}\right)$ se refere ao valor numérico, variando de 0 a 5 , atribuído a um agente causador de deterioração na estrutura de concreto. A ponderação do dano decorre do fato de que uma mesma ação deletéria, acometendo diferentes elementos estruturais, pode trazer prejuízos mais significativos ou menos impactantes no tocante à segurança, funcionalidade, estética e estabilidade estruturais. 
O Fator de intensidade do dano (Fi) se refere ao valor numérico, variando de 1 a 4, utilizado para mensurar a gravidade e o ritmo de evolução de um determinado dano. Diferentemente do $F_{p}$, o $F_{i}$ não apresenta variação de valor em função do elemento estrutural acometido; é, portanto, uma qualificação inerente à ação deletéria.

O Grau do Dano é calculado em função dos fatores de ponderação e de intensidade, sendo que o Grau de deterioração do elemento $\left(\mathrm{G}_{\mathrm{de}}\right)$ é calculado considerando-se a influência de todos os danos atuantes sobre um mesmo elemento, conforme Equação 1, e classificado conforme a Tabela 1.

$$
\mathrm{G}_{\mathrm{de}}=\mathrm{D}_{\text {máx }}\left[1+\frac{\left(\sum_{\mathrm{i}=1}^{\mathrm{n}} \mathrm{D}_{\mathrm{i}}\right)-\mathrm{D}_{\text {máx }}}{\sum_{\mathrm{i}=1}^{\mathrm{n}} \mathrm{D}_{\mathrm{i}}}\right]
$$

Sendo:

(Equação 1)

$\mathrm{G}_{\mathrm{de}} \quad$ Grau de deterioração do elemento [adimensional]

$\mathrm{D}_{\mathrm{i}} \quad$ Grau do dano de índice 'i' $\left(\mathrm{D}=0,8 \cdot \mathrm{F}_{\mathrm{i}} \cdot \mathrm{F}_{\mathrm{p}}\right)$ [adimensional]

$\mathrm{D}_{\text {máx }} \quad$ Maior grau de dano associado ao elemento [adimensional]

$\mathrm{n} \quad$ Número de danos encontrados no elemento [adimensional]

Tabela 1 - Classificação do grau de deterioração do elemento

\begin{tabular}{c|c|l}
\hline Nível de deterioração & $\mathbf{G}_{\text {de }}$ & \multicolumn{1}{c}{ Ações a serem adotadas } \\
\hline Baixo & $0-15$ & Estado aceitável. Manutenção preventiva \\
\hline Médio & $15-50$ & $\begin{array}{l}\text { Definir prazo para nova inspeção. Planejar intervenção em longo prazo } \\
\text { (máximo 2 anos) }\end{array}$ \\
\hline Alto & $50-80$ & $\begin{array}{l}\text { Definir prazo para inspeção especializada detalhada. Planejar intervenção em } \\
\text { médio prazo (máximo 1 ano) }\end{array}$ \\
\hline Sofrível & $80-100$ & $\begin{array}{l}\text { Definir prazo para inspeção especializada detalhada. Planejar intervenção em } \\
\text { curto prazo (máximo 6 meses) }\end{array}$ \\
\hline Crítico & $>100$ & $\begin{array}{l}\text { Inspeção especializada imediata com adoção de medidas emergenciais } \\
\text { (escoramentos, alívio de cargas, etc). }\end{array}$ \\
\hline
\end{tabular}

Fonte: Adaptado de Clímaco et al (2015)

O Grau de deterioração de uma família de elementos é calculado considerando-se os danos que acometem todos os elementos estruturais pertencentes a um mesmo grupo ou categoria, considerando o $\mathrm{G}_{\mathrm{de}}$ associado a cada elemento individual.

O Fator de relevância estrutural consiste em um valor atribuído a cada uma das famílias, considerando a relevância de seus elementos no comportamento e na estabilidade da estrutura global. Clímaco et al (2015) definem os valores do $\mathrm{F}_{\mathrm{r}}$ apresentados na Tabela 2.

Tabela 2 - Fatores de relevância estrutural das famílias de elementos

\begin{tabular}{l|c}
\hline \multicolumn{1}{c}{ Família } & $\mathbf{F r}_{\mathbf{r}}$ \\
\hline Barreiras, guarda-corpo, guarda-rodas, pista de rolamento e elementos arquitetônicos & 1 \\
\hline Juntas de dilatação e reservatório superior & 2 \\
\hline Transversinas, cortinas, alas, escadas, rampas, reservatório inferior e lajes secundárias & 3 \\
\hline Lajes, fuundações, vigas secundárias, pilares secundários e aparelhos de apoio & 4 \\
\hline Vigas principais e pilares principais & 5 \\
\hline
\end{tabular}

Fonte: Adaptado de Clímaco et al (2015)

O Grau de deterioração da estrutura corresponde à avaliação quanti-qualitativa final do estado de conservação estrutural, em face dos danos nela constatados, sendo calculado conforme a Equação 2. Segundo Clímaco et al (2015), após a determinação do $G_{d}$ para a estrutura global pode-se verificar o conjunto de atividades com o objetivo de recuperar a durabilidade e prolongar a vida útil estrutural. A classificação do $\mathrm{G}_{\mathrm{d}}$ é feita de acordo com a Tabela 3 . 


$$
\mathrm{G}_{\mathrm{d}}=\frac{\mathrm{K}_{\text {máx }}}{7,07} \sqrt{1+\frac{\left(\sum_{1=1}^{\mathrm{k}} \mathrm{K}_{\mathrm{i}}\right)-\mathrm{K}_{\text {máx }}}{\sum_{\mathrm{i}=1}^{\mathrm{k}} \mathrm{K}_{\mathrm{i}}}}
$$

(Equação 2)

Sendo:

$\begin{array}{ll}\mathrm{G}_{\mathrm{d}} & \text { Grau de deterioração da estrutura [adimensional] } \\ \mathrm{k} & \text { Número de famílias da estrutura [adimensional] } \\ \mathrm{K}_{\text {máx }} & \text { Maior valor do produto entre o } \mathrm{G}_{\mathrm{df}, \mathrm{i}} \text { o o } \mathrm{F}_{\mathrm{r}} \text { respectivo da família [adimensional] }\end{array}$

Tabela 3 - Classificação do grau de deterioração da estrutura e programa de ações

\begin{tabular}{c|c|l}
\hline Nível de deterioração & $\mathbf{G}_{\mathbf{d}}$ & \multicolumn{1}{c}{ Açães a serem adotadas } \\
\hline Baixo & $0-15$ & Estado aceitável. Manutenção preventiva \\
\hline Médio & $15-50$ & $\begin{array}{l}\text { Definir prazo para nova inspeção. Planejar intervenção em longo prazo } \\
\text { (máximo 2 anos) }\end{array}$ \\
\hline Alto & $50-80$ & $\begin{array}{l}\text { Definir prazo para inspeção especializada detalhada. Planejar intervenção em } \\
\text { médio prazo (máximo 1 ano) }\end{array}$ \\
\hline Sofrível & $80-100$ & $\begin{array}{l}\text { Definir prazo para inspeção especializada detalhada. Planejar intervenção em } \\
\text { curto prazo (máximo 6 meses) }\end{array}$ \\
\hline Crítico & $>100$ & $\begin{array}{l}\text { Inspeção especializada imediata com adoção de medidas emergenciais } \\
\text { (escoramentos, alívio de cargas, etc.). }\end{array}$ \\
\hline \multicolumn{2}{|c}{ Fonte: Adaptado de Clímaco et al (2015) }
\end{tabular}

\section{ESTUDO DE CASO}

O edifício objeto de estudo localiza-se no bairro Asa Sul da cidade de Brasília - DF. De ocupação residencial, o edifício é composto por seis pavimentos residenciais mais um pilotis, quantificando um total de 36 apartamentos. Estruturalmente, o sistema construtivo adotado na execução do edifício foi o de concreto armado, com fechamentos em alvenaria de bloco cerâmico de vedação. A Figura 6 apresenta a fachada frontal do edifício, utilizada como entrada principal.

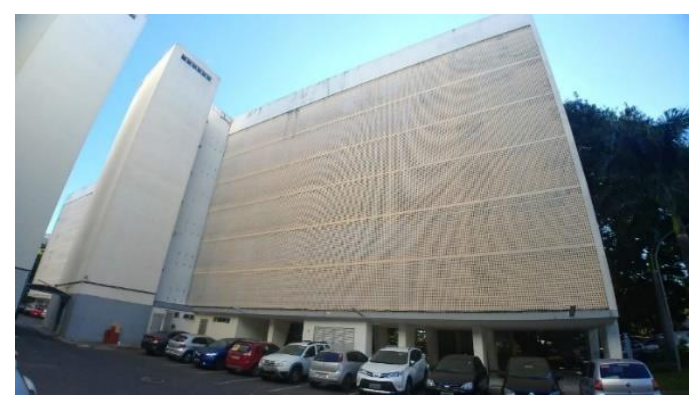

Figura 6: Edifício da Asa Sul em Brasília - DF Fonte: Do autor (2019)

De modo a estabelecer melhores critérios para a inspeção da edificação e a aplicação da metodologia GDE/UnB, a estrutura do edifício foi dividida em seis regiões de análise, a saber: reservatórios, casa de máquinas, cobertura, pavimentos tipo (apenas áreas comuns de circulação), pilotis e fachadas, conforme a Figura 7.

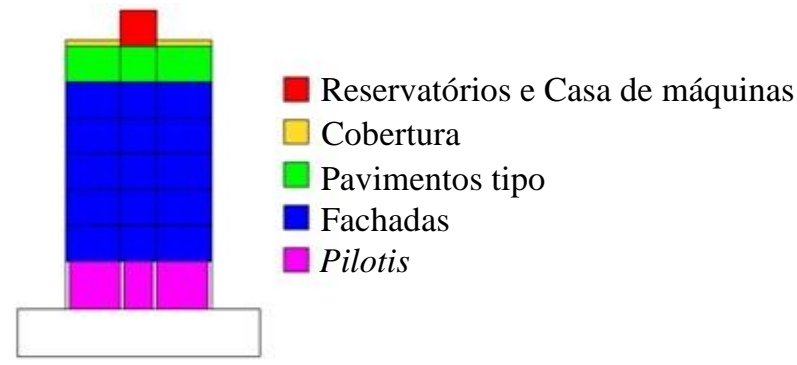

Figura 6: Divisão da estrutura da edificação para análise Fonte: Do autor (2019) 
Foi estabelecida uma nomenclatura atribuída a cada elemento inspecionado, com o objetivo de facilitar a identificação e localização deste na totalidade estrutural analisada. Essa nomenclatura é formada pelo tipo do elemento (viga, pilar, laje, fachada, por exemplo) seguida de um número indicador da sequência inspecionada (do primeiro ao último elemento considerado) e um sufixo associado à região de análise, a saber: R (Reservatório), CM (Casa de Máquinas), C (Cobertura), T (Pavimentos Tipo), P (Pilotis) e F (Fachadas).

Mediante a documentação fotográfica dos elementos inspecionados e acometidos de manifestações patológicas de variadas magnitudes, e baseando-se nos fatores de intensidade associados à cada agente de degradação estrutural, procedeu-se à valoração do grau de deterioração estrutural da edificação.

Com a determinação do grau de deterioração estrutural a níveis local e global, propôs-se também sugestões de intervenção para a recuperação parcial da durabilidade dos elementos, visando otimizar o desempenho dos sistemas edilícios quanto à segurança e usabilidade e prolongar a vida útil da edificação.

\section{RESULTADOS}

Embora a metodologia GDE/UnB seja utilizada predominantemente na avaliação de estruturas de concreto armado, as paredes de alvenaria de bloco cerâmico, utilizadas no fechamento da edificação, foram consideradas na avaliação das falhas identificadas no edifício, sendo estas paredes incluídas na família de elementos de composição arquitetônica.

A sequência de figuras a seguir exemplifica algumas das manifestações patológicas verificadas em elementos inspecionados em cada uma das seis regiões de análise da edificação.

A Figura 7 evidencia a ocorrência de desplacamento do concreto e de manchas de eflorescência na laje $01 \mathrm{R}$.
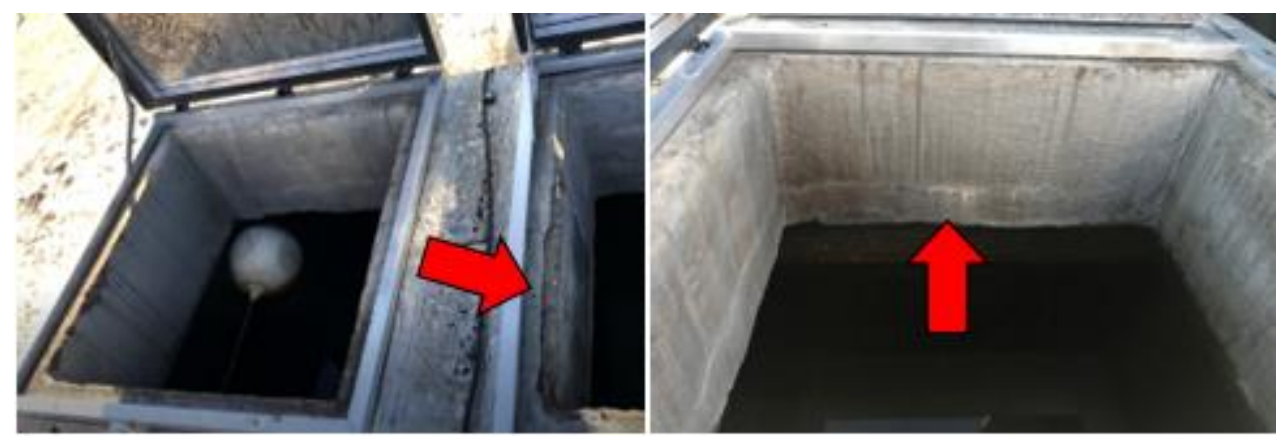

Figura 7: Manifestações patológicas nos reservatórios superiores

Fonte: Do autor (2019)

A Figura 8 indica a ocorrência de manchas de infiltração na laje $01 \mathrm{CM}$ e fissura na junção entre o fechamento de alvenaria e a viga de concreto armado, localizada na parede $04 \mathrm{CM}$.

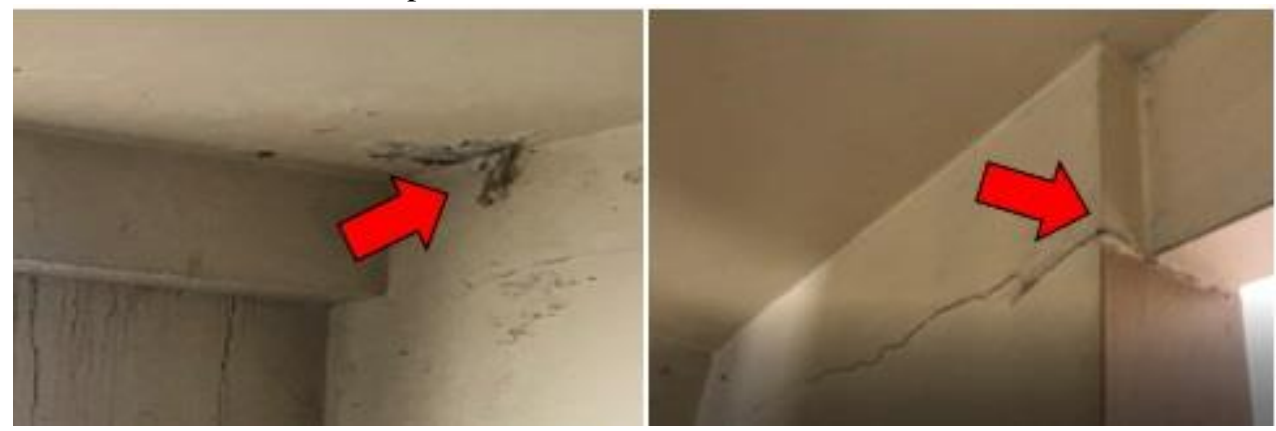

Figura 8: Manifestações patológicas na casa de máquinas

Fonte: Do autor (2019) 
A Figura 9 apresenta a ocorrência de fissuras na parede $013 \mathrm{~T}$, anomalia que se verifica no terceiro, quarto, quinto e sexto pavimentos tipo, e o preenchimento incorreto da junta de dilatação $02 \mathrm{~T}$, verificada no sexto pavimento tipo.
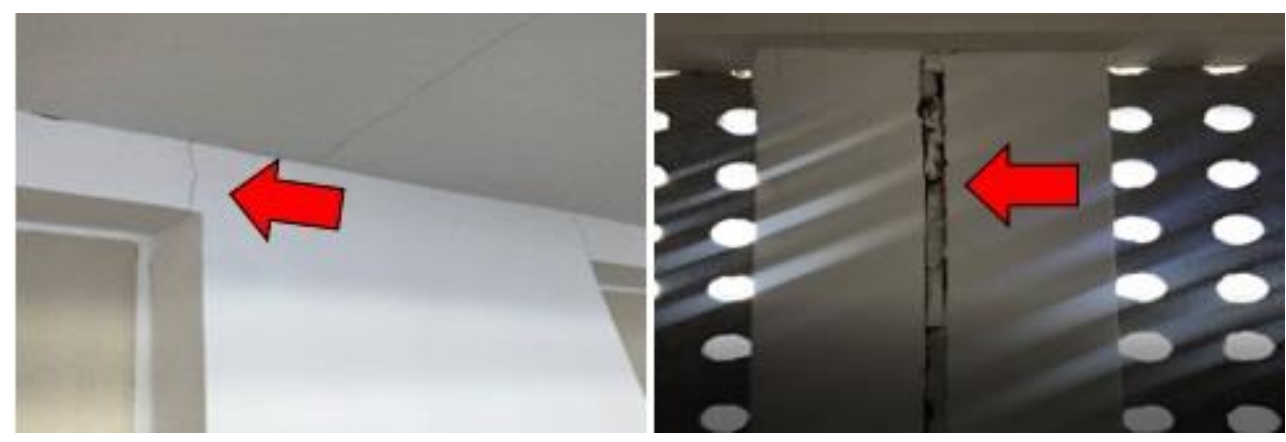

Figura 9: Manifestações patológicas nos pavimentos tipo

Fonte: Do autor (2019)

A Figura 10 evidencia a ocorrência de manchas de infiltração na laje $01 \mathrm{P}$ e de desplacamento do concreto na laje 03 P, com esta anomalia acompanhando todo o perímetro ao longo do beiral.

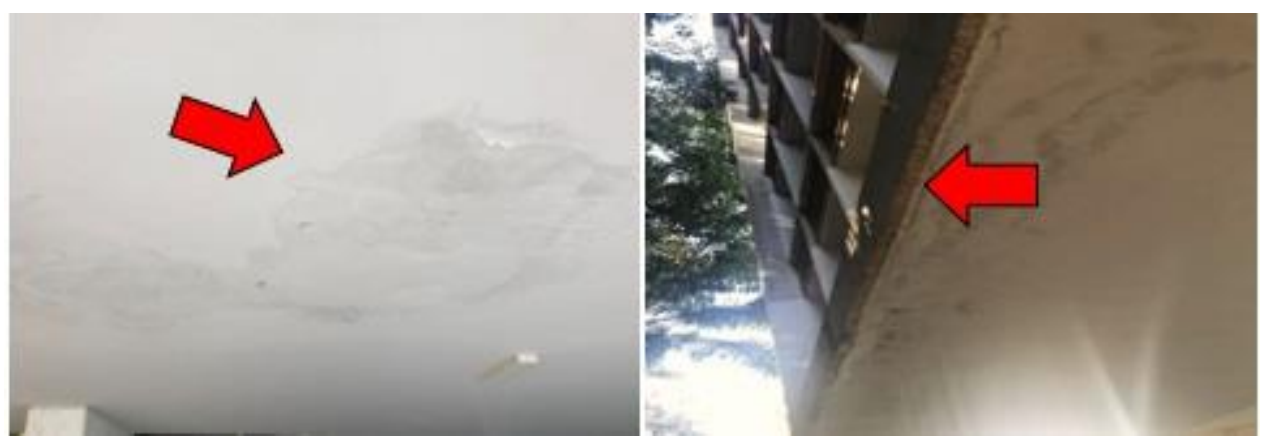

Figura 10: Manifestações patológicas no pilotis

Fonte: Do autor (2019)

A Figura 11 indica a ocorrência de extensas manchas escuras na parede $01 \mathrm{~F}$ da fachada frontal, além de manchas dispostas na base dos painéis de concreto, localizadas na parede $02 \mathrm{~F}$ da fachada posterior.

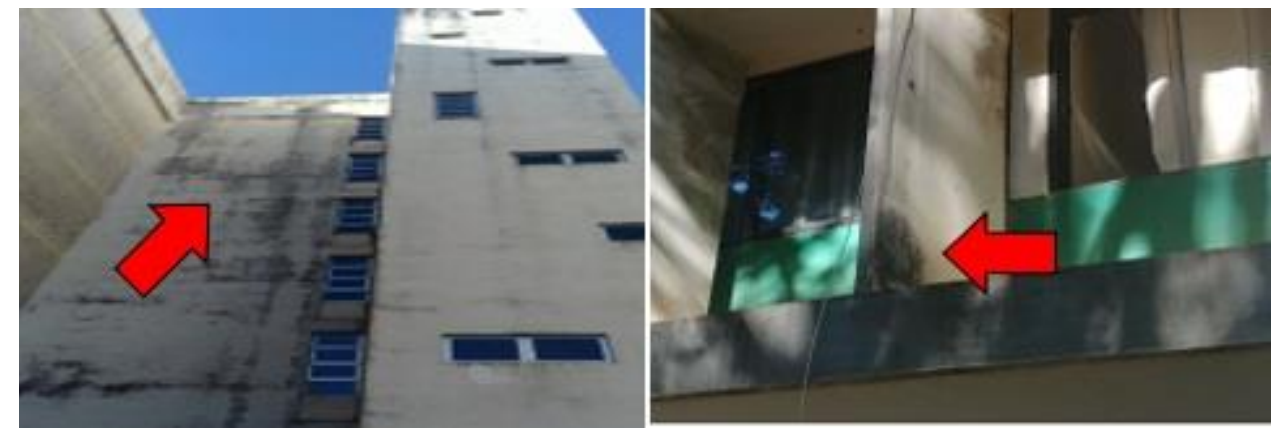

Figura 11: Manifestações patológicas nos pavimentos tipo

Fonte: Do autor (2019)

As tabelas apresentadas a seguir indicam os valores obtidos para os graus de deterioração a níveis individual, local e global. A Tabela 4 indica o $\mathrm{G}_{\mathrm{de}}$ calculado para cada um dos elementos inspecionados no conjunto estrutural do edifício, separados por tipo de elemento. A Tabela 5 aponta o grau de deterioração determinado para cada uma das regiões de análise nas quais a edificação foi dividida, considerando o conjunto dos elementos inspecionados em cada uma dessas regiões. 
Tabela 4 - Grau de deterioração dos elementos inspecionados

\begin{tabular}{|c|c|c|c|c|c|}
\hline Elementos & Lajes & Vigas & Pilares & Juntas de dilatação & Elementos de composição arquitetônica \\
\hline $\mathbf{G}_{\mathbf{d e}}$ & 12,7 & 4,8 & 4,8 & 8,0 & 6,7 \\
\hline $\mathbf{G}_{\mathrm{de}}$ & 3,6 & - & - & 8,0 & 7,2 \\
\hline $\mathbf{G}_{\text {de }}$ & 7,2 & - & - & 8,0 & 3,2 \\
\hline $\mathbf{G}_{\text {de }}$ & 7,2 & - & - & - & 16,0 \\
\hline $\mathbf{G}_{\text {de }}$ & 4,8 & - & - & - & 3,2 \\
\hline $\mathbf{G}_{\mathrm{de}}$ & 4,8 & - & - & - & 3,2 \\
\hline $\mathbf{G}_{\text {de }}$ & - & - & - & - & 3,2 \\
\hline $\mathbf{G}_{\mathbf{d e}}$ & - & - & - & - & 3,2 \\
\hline Gde & - & - & - & - & 3,2 \\
\hline $\mathbf{G}_{\text {de }}$ & - & - & - & - & 4,8 \\
\hline $\mathbf{G}_{\text {de }}$ & - & - & - & - & 24,0 \\
\hline Gde & - & - & - & - & 4,88 \\
\hline $\mathbf{G}_{\text {de }}$ & - & - & - & - & 19,7 \\
\hline
\end{tabular}

Fonte: Do autor (2019)

Tabela 5 - Graus de deterioração das regiões do edifício objeto de estudo

\begin{tabular}{c|c}
\hline Região da edificação & $\mathbf{G}_{\mathbf{d}}$ \\
\hline Reservatórios superiores & 3,6 \\
\hline Cobertura & 2.0 \\
\hline Casa de máquinas & 4,9 \\
\hline Pavimentos tipo & 4,2 \\
\hline Pilotis & 7,8 \\
\hline Fachadas & 6,0 \\
\hline
\end{tabular}

Fonte: Do autor (2019)

A Tabela 6 aponta o grau de deterioração determinado para cada uma das famílias de elementos ( $\left.\mathrm{G}_{\mathrm{df}}\right)$, conforme o tipo de elemento, assim como o grau de deterioração global $\left(\mathrm{G}_{\mathrm{d}}\right)$ da estrutura, considerada em sua totalidade.

Tabela 6 - Graus de deterioração de uma família de elementos e da estrutura total do edifício

\begin{tabular}{c|c|c|c}
\hline Elemento inspecionado & $\mathbf{G}_{\mathbf{d f}}$ & $\mathbf{F}_{\mathbf{r}}$ & $\mathbf{K}$ (produto entre $\mathbf{G}_{\mathbf{d f}} \mathbf{e} \mathbf{F}_{\mathbf{r}}$ \\
\hline Lajes & 21,3 & 4 & 85,2 \\
\hline Vigas & 4,8 & 5 & 24,0 \\
\hline Pilares & 4,8 & 5 & 24,0 \\
\hline Juntas de dilatação & 13,3 & 2 & 26,6 \\
\hline Elementos de composição arquitetônica & 42,4 & 1 & 42,4 \\
\hline
\end{tabular}

Fonte: Do autor (2019)

A avaliação realizada conforme a metodologia GDE/UnB resultou em um grau de deterioração global da estrutura de 15,0. Segundo Clímaco et al (2015), este valor é de particular representatividade, por se referir simultaneamente ao limite superior do nível de deterioração baixo e ao limite inferior do nível de deterioração médio, conforme visto na Tabela 3.

\section{DISCUSSÃO DOS RESULTADOS}

Considerando o fato de que a edificação possui quase 60 anos, verificou-se que sua sujeição à vistoria para a identificação de elementos degradados foi pautada na necessidade de avaliar o grau de deterioração estrutural de um conjunto edificado cuja idade excedeu o tempo médio de vida útil estimado para estruturas similares, que é de 50 anos, segundo a NBR 15575-2 (ABNT, 2013). Os resultados obtidos indicaram que todas as seis regiões de análise do edifício apresentaram baixo nível de degradação local, embora o valor obtido junto à análise global da estrutura tenha demonstrado que a edificação se aproxima do nível de degradação médio.

O Gráfico 1 resume a distribuição percentual dos danos globais à estrutura do edifício, como consequência das manifestações patológicas constatadas nos diversos elementos vistoriados ao longo das sub-regiões da estrutura. 
Gráfico 1 - Distribuição percentual das manifestações patológicas na estrutura do edifício

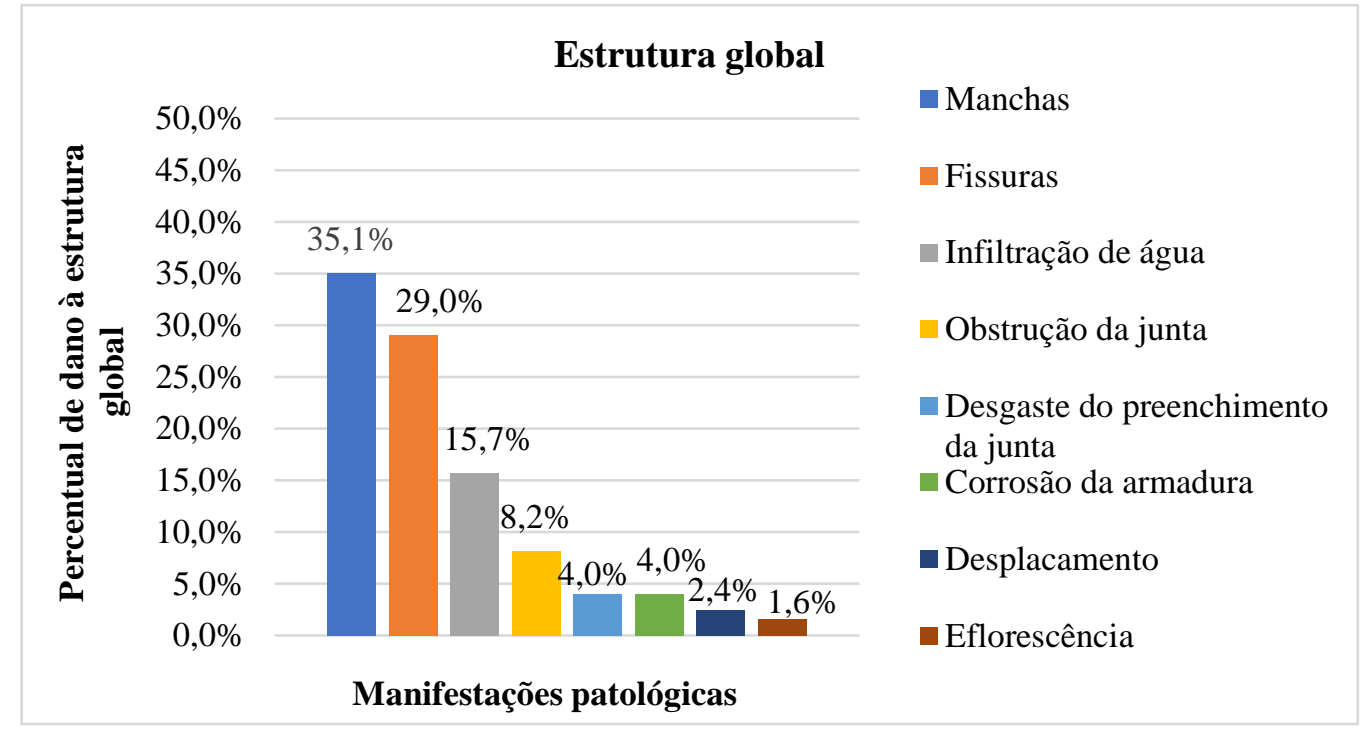

Fonte: Do autor (2019)

A análise do gráfico permite constatar que o edifício é caracterizado, no tocante à depreciação estrutural, por oito principais manifestações patológicas. Verifica-se que as manchas e as fissuras, somadas, representam mais da metade dos danos causados à estrutura da edificação devido às anomalias documentadas em sua composição

A análise global da estrutura, obtida mediante a ponderação das famílias de elementos inspecionados, totalizou um $\mathrm{G}_{\mathrm{d}}=$ 15,0, valor que representa a transição entre os níveis de deterioração baixo e médio. Assim, embora haja a indicação de que a estrutura do edifício ainda tem suportado adequadamente os danos provocados pelas manifestações patológicas, o estado aceitável não elimina a necessidade de intervenções, possibilitando aos administradores da edificação maior prazo quanto à programação das ações preventivas e corretivas a serem aplicadas aos elementos danificados, mediante a priorização de elementos e famílias com nível de deterioração médio $\left(\mathrm{G}_{\mathrm{d}}\right.$ maior ou igual a 15,0$)$.

A Tabela 7 apresenta algumas ações propostas para a mitigação dos danos já existentes e a prevenção quanto à ocorrência de novas manifestações patológicas, otimizando o desempenho e a durabilidade e prolongando a vida útil estrutural.

Tabela 7 - Intervenções propostas para a correção e prevenção das manifestações patológicas

\begin{tabular}{|c|l|}
\hline Manifestação patológica & \multicolumn{1}{c|}{ Ações preventivas e corretivas sugeridas } \\
\hline Manchas & $\begin{array}{l}\text { Realizar a limpeza com hidrojateamento e mapear as ocorrências, recompondo o sistema } \\
\text { de impermeabilização e eliminando microfissuras que permitem a entrada de água. }\end{array}$ \\
\hline Fissuras & $\begin{array}{l}\text { Abrir a trinca lateralmente. Retirar a poeira interna e aplicar material preparador à base } \\
\text { de água. Aplicar selante para vedar a trinca. Estender uma tela de poliéster sobre a trinca, } \\
\text { fixando-a com uma demão de impermeabilizante para parede e aplicar o acabamento. }\end{array}$ \\
\hline Infiltração de água & $\begin{array}{l}\text { Realizar manutenção do sistema de impermeabilização localizado acima dos trechos } \\
\text { danificados para sanar a deficiência da estanqueidade. Em seguida, proceder à } \\
\text { regularização da superfície danificada e à repintura. }\end{array}$ \\
\hline Obstrução e desgaste das & $\begin{array}{l}\text { Limpar o interior da junta. Remover o material rígido e desgastado utilizado no } \\
\text { fechamento externo da junta. Realizar selagem da junta com material elástico e flexível } \\
\text { (como o elastômero polimérico), capaz de absorver as deformações impostas à junta. }\end{array}$ \\
\hline juntas de dilatação & $\begin{array}{l}\text { Remover a superfície com a pequena mancha de corrosão e executar nova camada, com } \\
\text { cobrimento nominal maior, de 4,5 cm, conforme prescrição da NBR 6118 (ABNT, } \\
\text { 2014), mitigando a ação deletéria e conjunta do oxigênio e umidade às armaduras. }\end{array}$ \\
\hline Desplacamento & $\begin{array}{l}\text { Remover as camadas deterioradas de concreto e executar novas, com cobrimento } \\
\text { nominal maior, de 4,5 cm, conforme prescrição da NBR 6118 (ABNT, 2014). }\end{array}$ \\
\hline Eflorescência & $\begin{array}{l}\text { Recompor o sistema de impermeabilização externa do reservatório, impossibilitando o } \\
\text { fluxo de água para o interior do concreto. }\end{array}$ \\
\hline
\end{tabular}

Fonte: Do autor (2019) 


\section{AGRADECIMENTOS}

Agradecemos à empresa JR \& Chater Engenharia por disponibilizar e auxiliar na elaboração desta pesquisa.

\section{REFERÊNCIAS}

AITCIN, P. Concreto de Alto Desempenho. 1. ed. São Paulo: PINI, 2000.

ASSOCIAÇÃO BRASILEIRA DE NORMAS TÉCNICAS. NBR 15575-2: Edificações Habitacionais - Desempenho. Parte 2: Requisitos para os sistemas estruturais. Rio de Janeiro, 2013. 32 p.

ASSOCIAÇÃO BRASILEIRA DE NORMAS TÉCNICAS. NBR 6118: Projeto de estruturas de concreto Procedimento. Rio de Janeiro, 2014. 238 p.

ASSOCIAÇÃO BRASILEIRA DE NORMAS TÉCNICAS. NBR 9575: Impermeabilização - Seleção e projeto. Rio de Janeiro, 2010. 18 p.

CARDOSO, A. D. S. et al. Corrosão de Armaduras em estruturas de Concreto: Mecanismos e Tecnologias Para Proteção e Recuperação. XIII Congresso Internacional de Patologia e Reabilitação de Estruturas - CINPAR, Anais Vol. IA, Crato - CE, 2017. 438-460.

CARNEIRO, B. M. C.; D’ÁVILA, C. A. C.; LUIS, L. L. A Influência da NBR 15575:2013 nas Mudanças de Abordagem das Patologias em Edificações Habitacionais. XIII Congresso Internacional de Patologia e Reabilitação de Estruturas - CINPAR, Anais Vol. IA, Crato - CE, 2017. 321-334.

CASTRO, E. K. Desenvolvimento de Metodologia para Manutenção de Estruturas de Concreto Armado. Dissertação de Mestrado - Programa de Pós-Graduação em Estruturas e Construção Civil. Universidade de Brasília, 1994. $139 \mathrm{p}$.

CLÍMACO, J. C. T. S. et al. Manual de Aplicação da Metodologia GDE/UnB a Obras de Arte Especiais. Dissertação de Mestrado - Programa de Pós-Graduação em Estruturas e Construção Civil. Universidade de Brasília, 2015. 34 p.

CUNHA, A. J. P. et al. Acidentes estruturais na construção civil. São Paulo: PINI, v.1, 1996. 212 p.

FUSCO, P. B. Tecnologia do concreto estrutural: tópicos aplicados. 2.ed. São Paulo: PINI, 2012. 199 p.

ISAIA, G. C. Concreto: da era Clássica à Contemporânea. In: Concreto: Ensino, Pesquisa e Realizações. v. 1, São Paulo: IBRACON, 2005. 792 p.

NEVILlE, A. M. Propriedades do concreto. Tradução: Ruy Alberto Cremonini. 5. ed. Porto Alegre: Bookman, 2016. 888 p.

NEVILlE, A. M.; BROOKS, J. J. Tecnologia do concreto. Tradução: Ruy Alberto Cremonini. 2. ed. Porto Alegre: Bookman, 2013. $448 \mathrm{p}$

OLIVEIRA, C. F. et al. Manifestações Patológicas em Concreto Armado: Estudos de Casos de Carbonatação. XIII Congresso Internacional de Patologia e Reabilitação de Estruturas - CINPAR, Anais Vol. IB. Crato - CE, 2017. 424-441.

RIBEIRO, D. V. et al. Corrosão em Estruturas de Concreto Armado: Teoria, Controle e Métodos de Análise. 1. ed. Rio de Janeiro: Elsevier Brasil, 2014. 244 p.

SILVA, A. P.; JONOV, C. M. P. Patologia das Construções. Curso de Especialização em Construção Civil. Belo Hor izonte: Universidade Federal de Minas Gerais, 2011. 117 slides. Disponível em: <http://www.demc.ufmg.br/adriano/Pat ologia\%20das\%20Construcoes.pdf>. Acesso em 02 dez. 2019. 